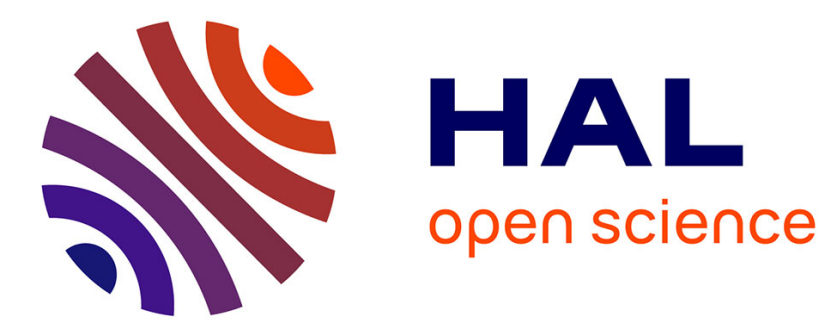

\title{
NONLINEAR PHOTOGENERATION OF CARRIERS IN AN INDIUM ANTIMONIDE ETALON
}

\author{
J. Hunter, H. Mackenzie, G. Allan, J. Hughes
}

\section{To cite this version:}

J. Hunter, H. Mackenzie, G. Allan, J. Hughes. NONLINEAR PHOTOGENERATION OF CARRIERS IN AN INDIUM ANTIMONIDE ETALON. Journal de Physique Colloques, 1988, 49 (C2), pp.C2-247-

C2-249. 10.1051/jphyscol:1988258 . jpa-00227675

\section{HAL Id: jpa-00227675 https://hal.science/jpa-00227675}

Submitted on 1 Jan 1988

HAL is a multi-disciplinary open access archive for the deposit and dissemination of scientific research documents, whether they are published or not. The documents may come from teaching and research institutions in France or abroad, or from public or private research centers.
L'archive ouverte pluridisciplinaire $\mathbf{H A L}$, est destinée au dépôt et à la diffusion de documents scientifiques de niveau recherche, publiés ou non, émanant des établissements d'enseignement et de recherche français ou étrangers, des laboratoires publics ou privés. 
NONLINEAR PHOTOGENERATION OF CARRIERS IN AN INDIUM ANTIMONIDE ETALON

\author{
J.J. HUNTER, H.A. MacKENZIE, G.R. ALLAN* and J.I.L. HUGHES \\ Department of Physics, Heriot-Watt University, Riccarton, \\ GB-Edinburgh EH14 $4 A S$, scotland, Great-Britain \\ ${ }^{*}$ CNRS-SNCI, 25, Avenue des Martyrs, BP 166X, F-38042 Grenoble. \\ France
}

\begin{abstract}
The photo-Hall technique has been used to investigate the properties of the InSb optical absorption band-edge. An accurate theoretical explanation of the linear absorption results is given, together with new data on the nonlinear aspects of the band-tail. A value of $1.1 \times 10^{-18}$ for $\sigma$ has been calculated by monitoring the carrier generation during bistability.
\end{abstract}

\title{
1 - INTRODUCTION
}

The measurement of photogenerated carrier populations using the photo-Hall method /1/ may be utilised both for the accurate measurement of optical absorption characteristics and for the monitoring of the logic state of optically bistable devices. In this paper we present new results for both linear and nonlinear optical absorption processes in $n-t y p e$ InSb. We also show how bistability can be monitored using the photo-Hall effect, and consider the device implications arising from this.

Linear optical absorption in InSb has been of research interest for three decades but the lower limit of conventional optical absorption measurements $\left(\alpha=0.1 \mathrm{~cm}^{-1}\right)$ has not yielded sufficient information about the absorption band-tail to make a detailed comparison with theory. In the present work the photo-Hall technique has been used to extend the measurable interband absorption to $\alpha=0.001 \mathrm{~cm}^{-1}$. Measurements have been made in uncompensated $\mathrm{n}$-type InSb $\left(\mathrm{N}=2 \times 10^{14} \mathrm{~cm}^{-3}\right)$ over the temperature range 20 to $77 \mathrm{~K}$ and the data for the $77 \mathrm{~K}$ experiment is shown in Figure' 1 .

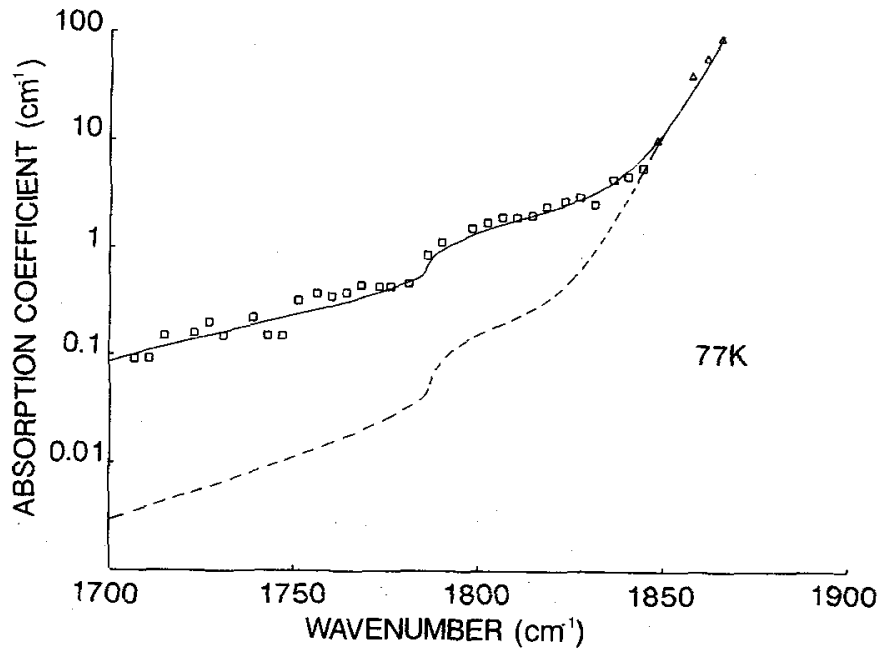

Fig. 1. The linear band edge for $77 \mathrm{~K} . \square$ are photo-Hall results; $\Delta$ are optical data. The solid line represents the full theoretical fit; the dashed line shows the form without phonon contribution. 
In general, the form of the absorption band tail over the complete temperature range consists of two distinct components: a spectral Urbach tail and, at lower absorptions, a broadened impurity contribution. The spectral Urbach contribution is of the form,

$\alpha(v)=A O \exp \left[\frac{\sigma}{\mathrm{kT}} \mathrm{c}\left(\mathrm{hv}-\mathrm{hv}_{0}\right)\right]$

where the parameters $A=20000 \mathrm{~cm}, \sigma=8$ and $v_{0}=1900 \mathrm{~cm}^{-1}$, and are of fixed value over the complete temperature range. This functional form gives excellent agreement with the experimental results in the appropriate higher absorption region. The feature observed at slightly lower frequencies has been identified as an acceptor impurity, with an ionisation energy of $8.1 \mathrm{meV}$. This suggests the presence of $\mathrm{Zn}$ and $\mathrm{Cd}$ in the material. The form of the impurity contribution has been analysed (after Eagles /3/) to establish the frequency dependence of the acceptor to conduction band optical transitions. When the effect of level broadening due to impurity interactions $/ 4 /$ is included, these two components accurately describe the band tail for temperatures below $\sim 40 \mathrm{~K}$. However, above this temperature, the theory departs from our experimental results, giving the dashed line shown in Figure 1 for $77 \mathrm{~K}$. Obviously there is a further contribution to the band tail which becomes more prominent with increasing temperature. It was found that the higher absorption can be explained by considering phonon assisted transitions, which depend strongly on temperature. Combining these three mechanisms for absorption, we have been able to accurately describe the band tail over the full experimental temperature range. The solid line shows the form of this theory for $77 \mathrm{~K}$. Thus the complete band tail of n-type InSb is formed from a spectral Urbach edge and a broadened acceptor impurity, with phonon assisteo. transitions making a further contribution above $40 \mathrm{~K}$.

Nonlinear optical absorption (and the associated intensity dependent refraction) has led to the development of optically bistable devices in InSb. The basic process is thought to be a dynamic Burstein-Moss shift of the band-edge, but this has not been confirmed unambiguously. In the present work, the form of the nonlinear optical absorption has been investigated at different regions of the band edge. In the higher region of the band tail, the absorption is seen to decrease with increasing intensity and this saturation has the same form as previously reported observations. The results at lower frequencies show a previously unseen increase in absorption with intensity.

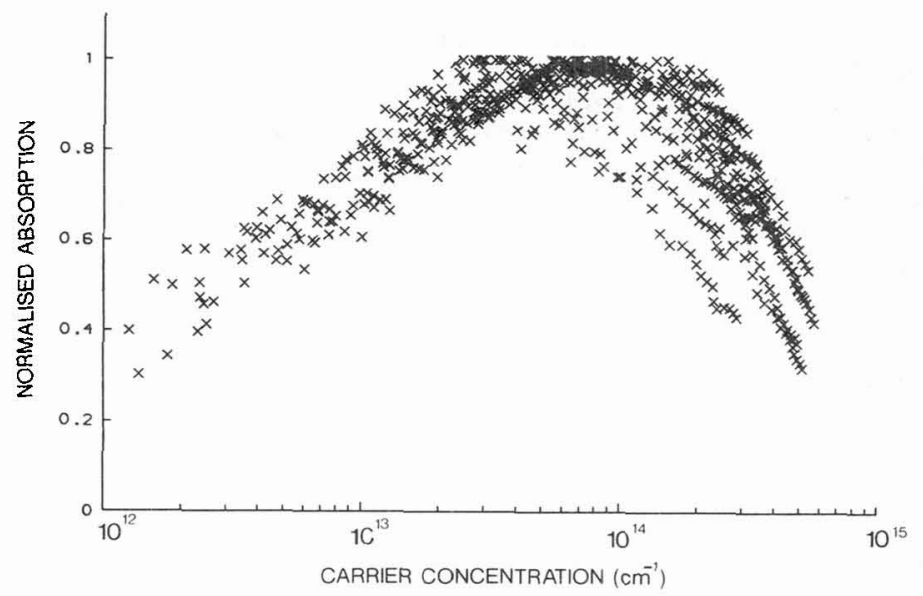

Fig. 2. Scatter diagram of absorption (normalised to the maximum at each frequency) versus carrier concentration for all recorded powers and frequencies.

The scatter diagram, Figure 2, shows the values of absorption (normalised to the maximum observed at each frequency) recorded over the full range of powers and frequencies, as a function of the induced carrier concentration. The absorption is seen to increase with carrier concentration up to populations of $7 \times 10^{13} \mathrm{~cm}^{-3}$, and to saturate beyond this point. This implies that it is the carrier concentration, and not the excitation frequency, which determines the form of the nonlinear absorption. A preliminary interpretation of the results suggests possible renormalisation or state broadening effects at photogenerated carrier populations below $7 \times 1013 \mathrm{~cm}^{-3}$, and that above this level, band blocking mechanisms prevail. 
When the photo-Hall technique is used with an optically bistable InSb etalon, the photocarrier generation through the bistable switch may be monitored directly. Figure 3 shows a typical experimental trace from such a device operating in the reflection mode where the increment of carriers $\left(21016 \mathrm{~cm}^{-3}\right)$ through the critical switch regime generates an output photo-Hall voltage of $25 \mu \mathrm{V}$ with an excellent signal to noise ratio.

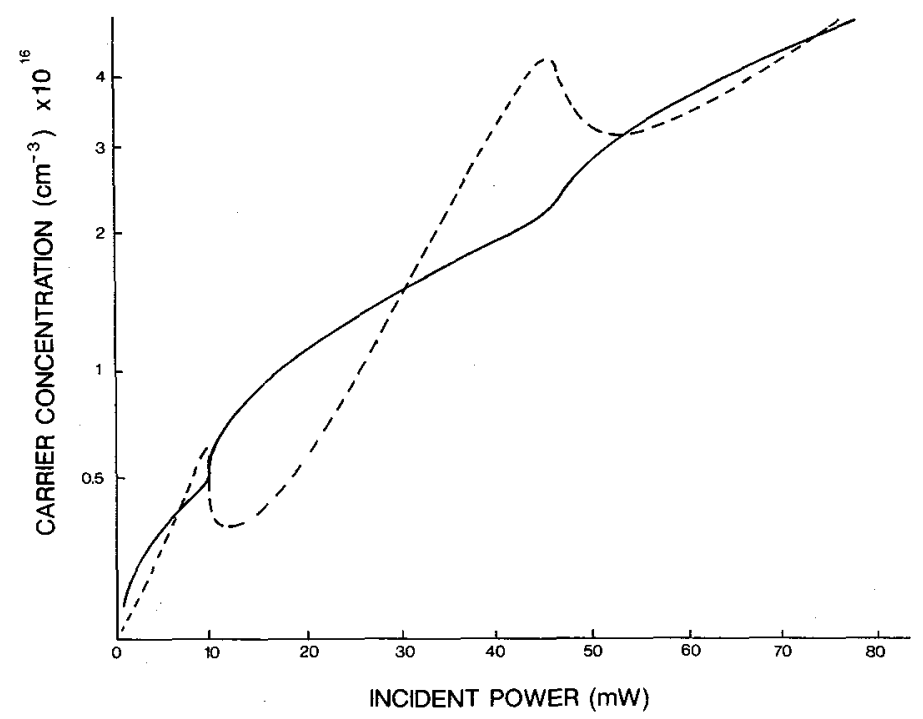

Fig. 3. Reflected optical (---) and photo-Hall (- $(-)$ signal through two orders of differential gain.

The technique may also be used to monitor the increment in carrier concentration between successive bistable switch points as illustrated in Figure 3 . The change in carrier concentration between these points relates to a change in refractive index through a full Fabry-Perot order. Since the magnitude of the change in index is known, the value of the nonlinear refractive cross-section, $\sigma$, can be calculated. The result above gives a value of $1.1 \times 10^{-18} \mathrm{~cm}^{3}$ for $\sigma$, which is consistent with earlier measurements $/ 6 /$.

The ability to electrically monitor the optical logic state is an important development in the evolution of an optically bistable optoelectronic (OBOE) interface with conventional computers. A new device is under development to directly activate and reset the optical logic state by external circuitry.

Using the photo-Hall technique, we have obtained new high resolution data for linear and nonlinear absorption in indium antimonide. A good theoretical description of the linear results has been developed, and work is continuing to achieve a more complete understanding of the nonlinear aspects. The carrier generation process in bistable switching has been observed, and we have calculated a value for the nonlinear refractive cross-section. The bistable device applications of the photo-Hall technique are also being developed.

\section{REFERENCES}

/1) MacKenzie, H.A., Allan, G.R., Hunter, J.J., Hutchings, D.C. and Wherrett, B.S., Opt. Commun., 63, 73 (1987).

12/ Johnson, E.J. and Fan, H.Y., Phys. Rev., 1349, A1991 (1965).

13/ Eagles, D.M., J. Phys. Chem. Solids, 16, 76 (1959).

14/ Lax, M. and Phillips, J.C., Phys. Rev., 110, 41 (1958).

15/ Dumke, W.P., Phys. Rev., 108, 1419 (1957).

16/ MacKenzie, H.A., Hagan, D.J. and Al-Attar, H.A., IEEE J. Quantum Electron, , 22, 8 (1986). 